
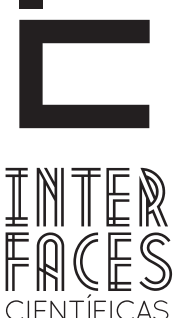

EXATAS E TECNOLÓGICAS

ISSN IMPRESSO - 2359-4934

E-ISSN - 2359-4942

DOI - 10.17564/2359-4934.2016v2n2p27-36

\title{
EFLUENTES DA INDÚSTRIA CANAVIEIRA DO ESTADO DE SERGIPE
}

Izaclaudia Santana da Cruz ${ }^{1}$ Roberto Rodrigues de Souza ${ }^{3}$
Isabel Cristina Barreto Andrade ${ }^{2}$ Gregório Guirado Faccioli ${ }^{4}$

\section{RESUMO}

A cana-de-açúcar é um dos principais produtos da economia de Sergipe no período atual; este fator preconiza desde o período colonial e tem um papel importante na atualidade por meio da inserção no agronegócio. Mas a ampliação dos canaviais para aumento da produção pode acarretar em problemas ambientais de poluição em cursos d'água, pela destinação irregular dos efluentes gerados após o beneficiamento da cana-de-açúcar. Para minimizar este impacto, se faz necessário um manejo desses resíduos que obedeçam aos critérios estabelecidos na legislação específica pertinente ao assunto, utilizando instrumentos tecnológicos como alternativas para redução desse risco. Nesse contexto, o presente trabalho teve como objetivo fazer um diagnóstico do manejo dos resíduos líquidos da produção sucroalcooleira em Sergipe e a partir da literatura sugerir estratégias para seu adequado reaproveitamento e tratamento. A pesquisa apresenta uma fundamentação teórica a partir de um levantamento bibliográfico sobre a temática proposta. A metodologia caracterizou-se como uma pesquisa descritiva e exploratória, por meio de pesquisa de campo e entrevista com os gestores das usinas pesquisadas. A análise e a discussão dos resultados debateram-se sobre a situação do manejo dos resíduos líquidos nas usinas sergipanas que possuem cadastro no Ministério da Agricultura. 


\section{PALAVRAS-CHAVE}

Agroindústrias. Cana-de-açúcar. Manejo de Resíduos.

\section{RESUMEN}

La caña de azúcar es uno de los principales productos de la economía Sergipe en el período actual; este factor prevalece desde el período colonial y tiene un papel importante en la actualidad mediante la introducción de la agroindustria. Sin embargo, la expansión de las plantaciones de caña de azúcar para aumentar la producción puede dar lugar a problemas de contaminación ambiental en los efluentes por disposición irregular de los residuos generados tras el procesamiento de la caña de azúcar. Para minimizar este impacto, un sistema de gestión de estos residuos que cumplan los criterios establecidos en la legislación específica pertinente al tema y el uso de herramientas tecnológicas como alternativas para reducir dicho riesgo es necesario. En este contexto, el presente estudio tuvo como objetivo realizar un diagnóstico de la gestión de los residuos líquidos de la producción

\section{ABSTRACT}

The sugarcane is one of the main products of the Sergipe economy in the current period; this factor calls from the colonial period and has an important role today by entering the agribusiness. But the expansion of sugarcane plantations to increase production can lead to environmental pollution problems in waterways by irregular disposal of waste generated after the processing of sugarcane. To minimize this impact, a management of these wastes that meet the criteria set out in the relevant legislation specific to de caña de azúcar en Sergipe y de la literatura sugieren estrategias para su reutilización y el tratamiento adecuado. La investigación presenta un fundamento teórico a partir de una revisión de la literatura sobre el tema. La metodología se caracteriza por ser una investigación descriptiva y exploratoria a través de la investigación de campo y entrevistas con los gerentes de las plantas encuestadas. La Análisis y discusión de los resultados se hicieron acerca de la situación de la gestión de los residuos líquidos en usinas de Sergipe que están asignadas al Ministerio de Agricultura.

\section{PALABRAS CLAVE}

Agroindustria, Caña de azúcar, Gestión de residuos.

the subject and using technological tools as alternatives to reduce such risk is necessary. In this context, this study aimed to make a diagnosis of management of liquid waste from sugarcane production in Sergipe and from the literature suggest strategies for its proper reuse and treatment. The research presents a theoretical foundation from a literature review on the subject proposal. The methodology was characterized as a descriptive and exploratory research through field research and interviews with manag- 
ers of the surveyed plants. Analysis and discussion of the results discussed on the situation of the management of liquid waste in Sergipe plants that have joined the Ministry of Agriculture.

\section{INTRODUÇ̄̃o}

A poluição dos recursos hídricos é um dos principais impactos ambientais causados pelo lançamento de efluentes industriais. Estes resíduos, oriundos das etapas de produção, possuem uma elevada carga de produtos químicos e matéria orgânica. Quando depositados sem tratamento nos corpos receptores causam a morte da fauna e flora aquática, comprometendo a preservação destes ecossistemas. Além disso, contaminam a água tornando-a imprópria para o consumo.

Ao verificar a necessidade do manejo adequado destes resíduos, é imprescindível a utilização de estratégias e tecnologias limpas, tendo em vista a minimizar os impactos ambientais desta atividade. Isso representa uma ferramenta importante para o desenvolvimento sustentável do setor agroindustrial canavieiro. Diante do exposto, este trabalho tem como objetivo fazer um diagnóstico do manejo dos resíduos líquidos da produção sucroalcooleira em Sergipe e a partir da literatura sugerir estratégias para seu adequado reaproveitamento e tratamento.

\section{RESÍDUOS AGROINDUSTRIAIS}

Os resíduos agroindustriais são gerados no processamento de alimentos, fibras, couro, madeira, produção de açúcar e álcool etc., sendo sua produção, geralmente, sazonal, condicionada pela maturidade da cultura ou oferta da matéria-prima (MATOS, 2005).

\section{KEYWORDS}

Agribusiness. Sugarcane. Waste management.

\subsection{EFLUENTES DA INDÚSTRIA CANAVIEIRA}

Com o crescimento da demanda por álcool e açúcar no Brasil, principalmente para atender o mercado internacional, as usinas canavieiras têm aumentado a sua produção. O setor canavieiro em Sergipe, também, está inserido neste processo de expansão das atividades sucroalcooleiras. Isso acarreta, entre outros problemas, no aumento da quantidade de resíduos gerados durante o processo industrial. Os resíduos da cana podem ser sólidos, líquidos ou gasosos.

Baseado no levantamento do Centro Tecnológico Canavieiro (CTC) em 1997, em média uma usina de pequeno porte que processa 1 milhão de tonelada de cana/ano e produz açúcar e álcool tem potencial de carga orgânica poluidora na safra equivalente a uma cidade com cerca de 1,5 milhões de habitantes (AGÊNCIA..., 2009). Diante disso, é necessário que as agroindústrias da cana adotem práticas de manejo destes resíduos com o objetivo de reduzir os impactos causados pela sua disposição inadequada no meio ambiente.

\subsubsection{VINHAÇA}

A palavra vinhaça é utilizada para designar o resíduo da destilação de uma solução alcoólica chamada vinho, obtida do processo de fermentação alcoólica. Também pode ser conhecida como vinhoto, garapão, restilo e outras denominações regionais (AGÊNCIA..., 2009). É rica em matéria orgânica e em nutrientes minerais como o potássio $(K)$, o cálcio $(\mathrm{Ca})$ e o enxofre 
(S), e possui uma concentração hidrogeniômica $(\mathrm{pH})$ variando entre 3,7 e 5,0 (LUDOVICE, 1996).

Uma aparente solução para o descarte racional na vinhaça é o que atualmente chama-se de fertirrigação, ou seja, a utilização desse produto rico em matéria orgânica aplicada in natura em áreas de plantio de cana.

A Companhia Ambiental do Estado de São Paulo (CETESB) ciente do problema ambiental da disposição inadequada de vinhaça nas lavouras de cana estabeleceu uma Norma, a P4. 231/2006, que estabelece critérios e procedimentos para a aplicação de vinhaça em solo agrícola. Esta norma estabelece, entre outros pontos, os locais em que não pode ser aplicada a vinhaça. Além disso, estabelece que devam ser realizados estudos para a avaliação da qualidade das águas subterrâneas e do solo.

Outra forma de reaproveitamento da vinhaça é a produção de biogás por meio da digestão anaeróbica da vinhaça. Este processo de biodisgestão anaeróbica da vinhaça possibilitará a obtenção de biogás de boa qualidade sem que os nutrientes da vinhaça sejam retirados desse efluente que poderá ser usado na fertirrigação.

A água utilizada em todas as etapas de produção de açúcar, álcool e co-geração de energia pode ter origem de poços subterrâneos ou de fontes superficiais. As águas superficiais captadas pelas usinas, parte é bruta e outra parte é tratada conforme as exigências do processo (AGÊNCIA..., 2009).

As águas residuarias da indústria canavieira são formadas pela soma de diversos efluentes líquidos industriais, atualmente compostos por purgas de sistemas fechados de lavagem de cana, purgas de circuitos de resfriamento, purgas do sistema de retentores de material particulado dos gases da chaminé, sobra de águas condensadas, flegmaça e lavagem de pisos (PIACENTE, 2005).

\subsection{TRATAMENTO DOS EFLUENTES DA INDÚSTRIA CANAVIEIRA}

As Resoluções CONAMA 357/2005 e 430/2011 estabelecem condições e padrões de lançamento de efluentes nos corpos hídricos. Por isso, as indústrias de beneficiamento de cana devem reaproveitar seus resíduos líquidos, evitando que eles sejam depositados inadequadamente nos afluentes (BRASIL, 2011).

A recuperação e tratamento dos despejos industriais das usinas e destilarias de cana são basicamente compostos por controles internos, ou seja, controle preventivo e os controles externos, que significam o tratamento dos efluentes. Esses tratamentos se resumem em: tratamento da água de lavagem da cana por decantação; o tratamento da água do lavador de gases das chaminés por decantação-flotação; os diversos resfriamentos, em torres de arrefecimento ou tanques aspersores; o efluente de lavagem de piso e equipamentos tratados em caixas de areis e gordura; e os esgotos domésticos conforme padronizado na Norma Brasileira sobre o assunto (AGÊNCIA..., 2009).

Além destes tratamentos as águas residuarias também podem ser aplicadas na lavoura de cana juntamente com a vinhaça. Com relação à vinhaça, a forma mais adequada como já foi dito anteriormente, é aproveitá-la no processo de fertirrigação das lavouras, obedecendo aos estudos de impactos ambientais nos solos e águas subterrâneas.

\section{MÉTODO}

\subsection{CARACTERIZAÇÃO DA ÁREA DE ESTUDO}

0 estudo foi realizado em todas as Agroindústrias Canavieiras de Sergipe cadastradas no Ministério da Agricultura, Pecuária e Abastecimento, no ano de 2014:

1) Usina São José do Pinheiro de Açúcar e Álcool Ltda. Laranjeiras/SE, produtora de açúcar e álcool. 
2) Usina Agroindustrial Campo Lindo Ltda. Nossa Senhora das Dores/SE, produtora de álcool.

3) Usina Termo Elétrica Iolando Leite. Capela/SE, produtora de álcool e aguardente.

4) Usina Junco Novo Ltda, Capela/SE, produtora álcool e aguardente.

5) Agroindustrial Capela (Destilaria Taquari), Capela/SE, produtora de álcool e aguardente.

6) Unidade Industrial da Companhia Brasileira de Açúcar e Álcool, Japoatã/SE, produtora de álcool hidratado e anidro.

\subsection{PROCEDIMENTOS METODOLÓGICOS}

Para que o objetivo principal do trabalho apresentado fosse atingido, foi realizada uma pesquisa descritiva, exploratória, baseada em estudo de caso. Essa alternativa foi escolhida devido a necessidade de identificar as principais ações realizadas pelas agroindústrias sucroalcooleiras sergipanas em relação aos seus resíduos líquidos.

Quanto aos meios, tratou-se de uma pesquisa bibliográfica e de campo. Bibliográfica, porque para a fundamentação teórico-metodológica do trabalho foi realizada investigação na literatura relacionada sobre os seguintes assuntos: atividade canavieira Sergipe, seus impactos ambientais e efluentes canavieiros e a forma de tratamento/destinação. De campo porque coletou e analisou dados pertencentes às agroindústrias canavieiras tomadas como estudo de caso, usando como instrumentos metodológicos a entrevista estruturada e a observação sistemática.

Inicialmente foi realizado um contato telefônico com funcionários das Usinas, nesse contato foi introduzida a temática da pesquisa a ser realizada e cogitou-se a possibilidade de participação em uma entrevista. Com a devida autorização dos gestores das usinas, foi realizada uma visita a campo com o objetivo de fazer a entrevista e conhecer as instalações da usina, bem como o processo industrial e a destinação das efluentes da indústria.

Os dados foram analisados estatisticamente, utilizando o cálculo de porcentagem para a tabulação dos dados. Em seguida, foram elaborados gráficos dos resultados e analisados conforme conhecimentos da literatura relacionada ao tema.

\section{ANÁLISE E DISCUSSÃO DOS RESULTADOS}

A agroindústria da cana-de-açúcar em Sergipe está restrita ao universo das seis principais usinas localizadas em algumas cidades em Sergipe. Estas são produtoras de álcool, açúcar ou aguardente. De maneira geral, são consideradas indústrias de pequeno e médio porte. Nesta pesquisa foi realizado um estudo de caso sobre as usinas sergipanas e buscou-se realizar o diagnóstico do tratamento e destinação dos efluentes do setor canavieiro: a vinhaça e as águas residuarias.

\subsection{SOBRE A VINHAÇA}

A vinhaça é um dos principais resíduos da atividade canavieira, tanto em quantidade como em qualidade. 0 primeiro porque é muito grande o volume de vinhaça gerado no beneficiamento da cana para a produção de álcool. De acordo com informações das usinas sergipanas durante a pesquisa, para cada litro de álcool produzido são gerados em média de 13 a 15 litros de vinhaça. E o segundo ponto importante é que a vinhaça é um resíduo rico em nutrientes.

A vinhaça possui um alto poder de contaminação, devido a isso, ela não deve ser lançada inadequadamente no solo ou águas superficiais e subterrâneas. Segundo a Resolução CONAMA 430, de 13 de maio de 2011, nos Arts. 2ํㅜ e 3a a disposição de efluentes no solo não pode causar poluição ou con- 
taminação das águas superficiais e subterrâneas, bem como os efluentes de qualquer fonte poluidora só poderão ser lançados diretamente nos corpos receptores após o devido tratamento e desde que obedeçam as condições, padrões e exigências dispostos nesta Resolução e em outras normas aplicáveis (BRASIL, 2011).

Sobre o item que aborda a maneira como reaproveitam este resíduo, $100 \%$ das usinas do Estado responderam que utilizam a vinhaça para fertirrigação das suas lavouras de cana. Elas demonstraram que obtiveram resultados satisfatórios nas áreas de plantio com a aplicação da vinhaça, além de ser uma alternativa utilizada para não lançar este resíduo diretamente no corpo hídrico (PARANHOS, 1987).

A próxima pergunta aos gestores foi sobre quais investimentos suas usinas têm realizado para uma melhor utilização deste resíduo. A Figura 1 ilustra os resultados deste questionamento.

Figura 1 - Investimentos para o Gerenciamento da Vinhaça

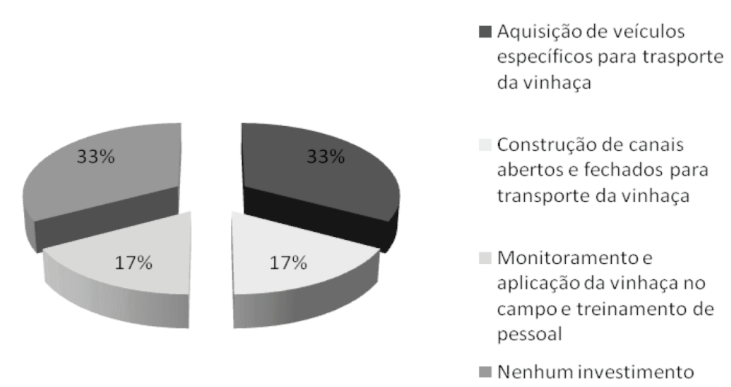

Fonte: Dados da pesquisa.

Os investimentos no monitoramento da aplicação de vinhaça ainda são pouco representativos diante da sua grande importância para as questões ambientais, visto que sem este monitoramento não há como se ter o controle do grau de contaminação que este resíduo pode causar ao solo e lençol de água.
Segundo ficou claro na pesquisa, outro ponto a se questionar é que algumas usinas, ou seja, $33 \%$ delas, ainda não investem em tecnologias para o manejo da vinhaça. Ainda com relação ao aproveitamento do vinhoto, os entrevistados responderam afirmativamente ou negativamente a outros questionamentos, conforme mostra a Figura 2.

Figura 2 - Gerenciamento da Vinhaça

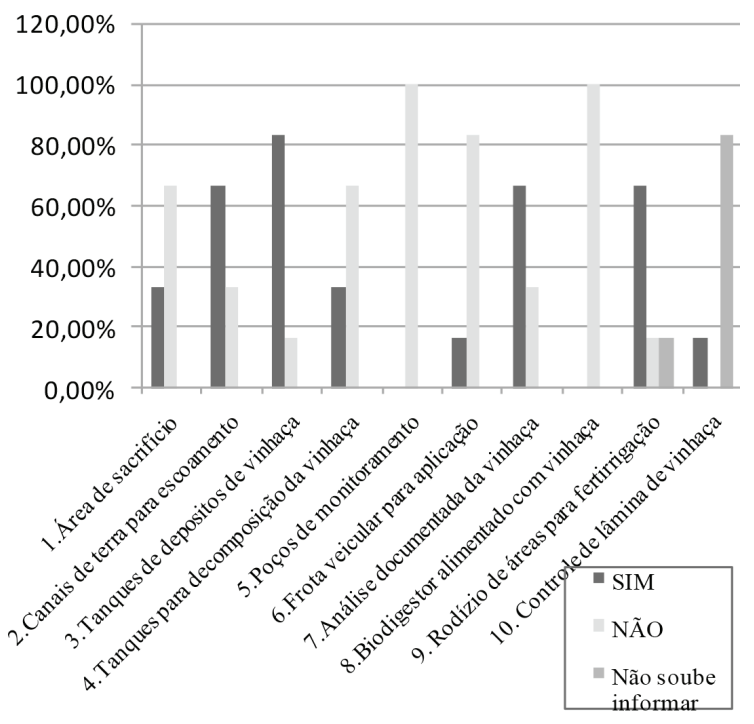

Fonte: Dados da pesquisa.

Ao observar os resultados obtidos na Figura 2, pode-se verificar primeiramente que a maioria das usinas entrevistadas não possui área de sacrifício da vinhaça. Outro ponto importante diz respeito à forma como as usinas transportam a vinhaça para o campo, sendo a utilização de canais a maneira mais comumente utilizada pelas agroindústrias para esse tipo de transporte. Apenas uma pequena parte delas faz uso de veículos para a realização desta atividade.

Com relação ao local para o armazenamento da vinhaça, constatou-se que grande parte dos entrevistados disse possuir tanques específicos para o armazenamento deste resíduo, antes de serem destinados 
para a fertirrigação. Já com relação aos tanques de decomposição da vinhaça apenas uma usina ainda possui esse tipo de tanque aberto e sem impermeabilização.

Um ponto preocupante com relação ao gerenciamento da vinhaça é o fato de nenhuma das usinas sergipanas possuírem poços de monitoramento de contaminação do lençol subterrâneo e do solo. Fica evidente a falta de preocupação com os problemas ambientais que essa ausência de controle pode acarretar. Além disso, algumas usinas no Estado não fazem análise documentada da vinhaça que está sendo utilizada nas suas lavouras de cana, como mostra a Figura 2.

Quando questionados sobre o rodízio de áreas com aplicação de vinhaça, a maior parte das usinas sergipanas afirmou que faz este tipo de revezamento.

Sobre o uso da vinhaça para a produção de biogás, por meio de um biodigestor, uma técnica já utilizada em outras regiões do país, $100 \%$ das usinas pesquisadas não utiliza esse sistema, apesar de algumas já terem conhecimento dessa forma de reaproveitamento.

Ao analisar os resultados desta pesquisa com relação ao gerenciamento da vinhaça nas agroindústrias em Sergipe fica evidente que elas já estão desenvolvendo práticas de reaproveitamento deste resíduo, evitando assim que ele seja descartado aleatoriamente no meio ambiente. Entretanto, é necessário um programa de ação mais eficiente e contínuo, ou seja, um plano de gestão da vinhaça visando o desenvolvimento sustentável (MOREIRA, 2004).

\subsection{SOBRE AS ÁGUAS RESIDUARIAS}

Um ponto importante para citar trata da lavagem da cana, um processo que utiliza muita água. Na maioria das usinas a cana vai para moagem como chega do campo, apenas em duas delas, as mais modernas, a cana é lavada antes de ser moída, sendo que em uma destas o circuito é fechado e na outra a água da lavagem vai para a irrigação.
Das usinas analisadas: aproximadamente 80\% afirmaram que as águas utilizadas na produção são reaproveitadas; as demais ainda não reutilizam a água do processo produtivo. Como já citado anteriormente, a água utilizada nas agroindústrias sergipanas são captadas em rios da região.

Assim, quanto menor o índice de reaproveitamento desta água maior será a captação nos corpos hídricos. Então, é fundamental que essa água seja primeiramente reaproveitada no processo, evitando a aumento da captação de água. A Figura 3 ilustra as formas de reaproveitamento da água pelas usinas em Sergipe.

Figura 3 - Reaproveitamento da Água nas Agroindústrias Canavieiras em Sergipe

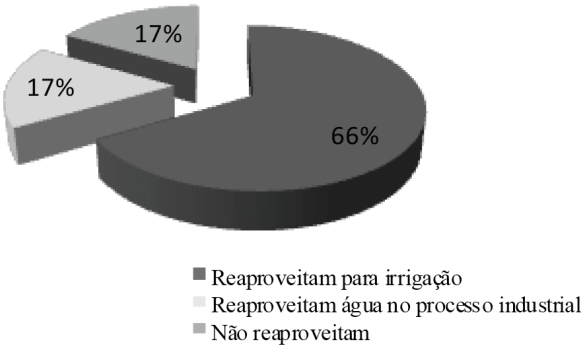

Fonte: Dados da pesquisa.

Segundo a Figura 3, apenas uma pequena porcentagem do total da usinas canavieiras reaproveitam a água novamente no processo. A grande maioria delas reutiliza a água para a irrigação. Sobre o tratamento das águas residuarias, as agroindústrias relataram que fazem o tratamento convencional e para diminuir a temperatura da água após o processo industrial utilizam a técnica de troca de calor com o meio ambiente.

\section{CONCLUSÕES}

Essa pesquisa preocupou-se em fazer um diagnóstico sobre o manejo dos resíduos líquidos gerados pela agroindústria da cana em Sergipe, a vinhaça e 
as águas residuarias. A legislação bem como o órgão ambiental do Estado de Sergipe não admite que esses efluentes sejam lançados no corpo hídrico, por isso as usinas precisam tratar e reaproveitá-los para reduzir os impactos ao meio ambiente de suas atividades produtivas.

Em relação à vinhaça nota-se a preocupação cada vez maior da sociedade científica com o risco que esse material altamente poluente pode causar aos cursos d'água superficiais por meio da percolação até as águas subterrâneas. Essa segunda preocupação é mais latente uma vez que esse tipo de poluição não é imediatamente notado e muitas vezes quando constatada, sua possibilidade de reversão é pequena.

Saídas tecnológicas são apontadas por muitos especialistas como a principal alternativa para se diminuir a carga orgânica desse resíduo e reutilizá-lo na fertirrigação com um menor risco de dano à natureza.

Diante do que foi verificado, observa-se que as usinas pesquisadas devem dar maior atenção ao manejo desses resíduos líquidos. Não adianta somente destinar esses efluentes para fertirrigação, acreditando ser essa é melhor forma de reaproveitá-los. Antes disso é preciso reduzir o consumo dos recursos hídricos e buscar alternativas para reutilizá-lo dentro processo industrial.

\section{REFERÊNCIAS}

AGÊNCIA Nacional de Águas - A.N.A. Manual de conservação e reuso de água na agroindústria sucroenergética. Agência Nacional de Águas; Federação das indústrias do Estado de São Paulo; União da indústria da cana-de-açúcar; Centro de Tecnologia Canavieira. Brasília: ANA, 2009. Disponível em: <http://www.unica.com.br>. Acesso em: nov. 2011.
BRASIL. Resolução CONAMA nº 313 de 29 de outubro de 2002, que dispõe sobre o inventário nacional de resíduos sólidos, semi-sólidos e gasosos industriais. Disponível em: <http://<www.mma.gov. br>. Acesso em: ago. 2011.

BRASIL. Resolução CONAMA nº 357 de 25 de Abril de 2005, que dispõe sobre condições e padrões de lançamento de efluentes. Disponível em: <http://<www.mma.gov.br>. Acesso em: ago. 2011.

\section{LUDOVICE, M.T. Estudo do efeito poluente da vinhaça infiltrada em canal condutor de terra sobre o lençol freático. 1996. Dissertação (Mestrado) - FEC-UNICAMP, Campinas-SP, 1996.}

\section{MATOS, A.T. Tratamento de resíduos agroindustriais.}

Curso sobre tratamento de resíduos agroindustriais, Viçosa-MG: UFV, 2005.

MINISTÉRIO da Agricultura, Pecuária e abastecimento - MAPA. Disponível em: <http://<www.agricultura.gov. br>. Acesso em: maio 2011.

\section{MOREIRA, C.Z. de O. Questões ambientais e} sustentabilidade da cana-de-açúcar em São Miguel dos Campos - Alagoas. 2004. 184f. Dissertação

(Mestrado em Geografia) - Núcleo de Pós-Graduação em Geografia, Pró-Reitoria de Pós-Graduação e Pesquisa, Universidade Federal de Sergipe, São Cristóvão-SE, 2004.

PARANHOS, Sergio Bicudo (Coord.). Cana-de-açúcar; cultivo e utilização. São Paulo: Fundação Cargill, 1987.

\section{PIACENTE, F.J. Agroindústria canavieira e o sistema} de gestão ambiental: o caso das usinas localizadas nas bacias hidrográficas dos rios Piracicaba, Capivari e Jundiaí. 2005. 177f. Dissertação (Mestrado) - Programa de Pós-Graduação em Desenvolvimento Econômico, Campinas-SP: UNICAMP, 2005. Disponível em: <http://<www.cori.unicamp.br>. Acesso em: jun. 2010. 
PRODUÇÃO AGRICOLA MUNICIPAL IBGE. Sistema IBGE de recuperação automática - SIDRA. Rio de Janeiro: IBGE. Disponível: <http://ww.ibge.gov.br>. Acesso em: maio 2009.

RODRIGUES, R. Bagaço e Álcool. Revista

Agroanalysis, São Paulo: ABAG - Associação

Brasileira de Agribisiness, dez. de 2001.
SÃO PAULO (Estado). Norma Técnica da CETESB P4. 231, de dezembro de 2006, que dispõe sobre Vinhaça - critérios e procedimentos para aplicação no solo agrícola, 2006. Disponível em: <http://<www.cetesb. sp.gov.br>. Acesso em: out. 2010. 
1. Doutora em Desenvolvimento e Meio Ambiente - Programa de Pós-Graduação em Desenvolvimento e Meio Ambiente (PRODEMA), da Universidade Federal de Sergipe - UFS; Tecnóloga em Saneamento Ambiental. E-mail: izaclaudiasantana@yahoo.com.br

2. Doutora em Desenvolvimento e Meio Ambiente - Programa de Pós-Graduação em Desenvolvimento e Meio Ambiente (PRODEMA), da Universidade Federal de Sergipe - UFS; Bacharel em Administração. E-mail: icbandrade@ yahoo.com.br

3. Doutor em Engenharia Química e Mestre em Engenharia Química - UNICAMP; Graduado em Engenharia Química e Licenciatura em Química e Professor da Universidade Federal de Sergipe - UFS. E-mail: jpbioma@ufs.br

4. Doutor em Engenharia Agrícola; Mestre em Engenharia Agrícola; Graduado em Engenharia Agrícola - UFS; Professor da Universidade Federal de Aceito em: 2 de Abril de 2016 